\section{TOWARDS MORE EFFECTIVE MATHEMATICS EDUCATION}

\section{S. Close}

The effects of our teaching programme are frequently distrtrous -.-. The students have no sense of history of the subject, nor its origins. They see no relationship between mathematics and the world in which we live. They are continually confronted with definitions and theorems their historical and quite valid completely cut off from their historical and quite valid origins... But worst of all we kill any enthusiasm our students have for the subject which we present as a logical and pedestrian development of results from an apparentiy axitrary base made up of some axioms."

We have become convinced that a major contribution to he difficulties that students are having (in first univerthe difficulties that stom their grasp, or rather lack sity Physics courses) comes from their grasp, or racher lack of the fundamentals of mathematics. --- We have discovered an appalling lack of the most elementary mathe [10]

"You who are reading this most likely know what's wrong ith secondary school mathematics in Ireland. The only question you need to have answered now is: When is something going to be done about it?" appeared in recent issues of the Irish Mathematical Society there are serious problems in matheming at both the second and third levels of schoolatics education at both the second and third ing. Indeed, at second-level, the Government Department of Education Syllabus Committee in Mathematics is presently the existing syllabus. result of criticisms from university mathematics departments, colleges of technology, post-primary teacher associations (including the Irish Mathematics Teachers Association), and industrial bodies. Despite the lack of formal research evidence it seems clear enough that many students are failing to learn mathematics effectively in our schools and colleges at the present time. It is also apparent that many educators and employers accept this situation as inevitable and as an artifact of innate human variability and even see it as desirable for differentiation and selection purposes. For those who would seek to improve on the present system I would like to clarify some of the educational variables involved and make a few suggestions on how educational theory might be drawn upon to derive models and principles (many of which have been well researched) for addressing these variables in facilitating mathematics learning.

Writing in the 69th Yearbook of the National Society for the Study of Education in the U.S.A., Lee S. Shulman described "a model for examining those variables which must be considered in formulating any propositions about the best forms of (mathematics) instruction" [11]. A diagram of the model is presented in Fig. 1 below.

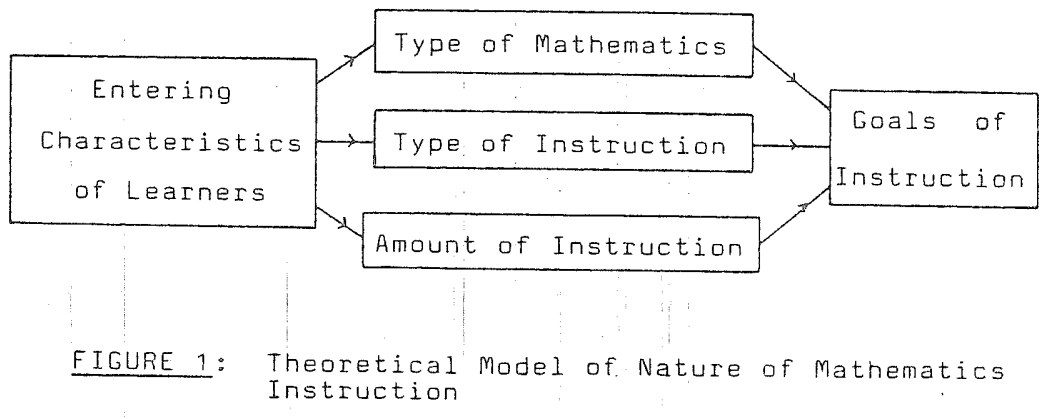

In accordance with this model mathematics instruction is viewed as a complex interaction of variables which can be 
categorised under the headings: mathematical content, learning environment, time for learning, results of learning, and, the The problem of building mathematical and statistithe nature of the relationcal models to describe and examie model of the instructional ships in this kind of theoretical model of the instructional process has proved to be more comlex and dif icult than is the case with models of physical and natural processe of empir educational research literature is laden with reports of enpir ical studies in which carefully formulated hypotheses find no on the other hand support in the data collected and analysed. there are also many reports of studies yielding clearcut findings which can be used to develop more effective instructional iation of America and the National Council of Teachers of Mathematics, E.G. Begle [1] and his colleagues at stanford compical literature ensively reviewed the (largely American) empirical literature in mathematical education in which they categorised the above ings under headings somewhat similar to those of the aboves of the model based on interpretations of existing educa and research.

selection of matr ype of Mathematical Content: The selection of mathenatical content for courses is an aspect of mathenaticad education which is often fraught with controversies and difficulties. This is understandable when one considers the wide range of of mathematical topics available, the wide range of abilities of learners and the rapid development of modern society. psychologeducational theory suggests that logical structure, psychological factors, and sociological factors should decisions for varemphasis and consideration in making content decisions for var ious groups of students. Mathematicians would argue that as one moves further up the mathematical ladder' the The Interant the logical structure of the content becomes. nediate Certificate course in geometry has come in for strong crits due to its apparent lack of structure and cohesive ness [3].
In regard to the psychology of learning mathematics, it can be argued that, since mathematics is a highly structured subject, serious effort should be made to choose, organise and place topics so that students or groups of students can be fairly accurately located on a continuum of knowledge acquisition (or mathematical development) appropriate to the past achievements. We do not pay nearly enough attention to the notions of continuity and of maintenance of acquired knowledge in the business of syllabus/curiciculum design. Many of the learning problems in second and third level courses are probably related to the lack of a number of very basic prerequisite skills and items of knowledge which could easily be incorporated into syllabi and given some attention (manipulation of algebraic expressions and of quantities expressed in scientific notation are two often-mentioned ones at first-year college level).

From a sociological viewpoint, the significance or relavance of a topic should be another consideration in making decisions about syllabus content. The relevance or significance of a topic resides in its historical origins, in its usefulness in society, in its applications in technology and in its intrinsic appeal. Finally, I would argue that, to some extent, the more attention given to logical coherence, meaningfulness, and relevance in syllabus design the more successful will students be in learning the syllabus content. It might also be added that there is a need to consider the interaction of content selection considerations and student characteristics. For example, some students seem to learn mathematics more effectively when the relevance of the topic is stressed.

Goals of Instruction: The specification of the desired outcomes of a course/programme in mathematics should consist of something more concise and more tangible than a listing of mathematical content topics. The inclusion of reference to the levels of cognitive complexity in relation to each content area helps to ensure a balanced coverage of the mathematics and facilitates instruction and assessment by delineating the 
range of tasks or class of problems under consideration. An example of a system of classification of levels of cognitive complexity which was used in the International Study of Achievment is given in Fig. 2.

Content Areas

1. Knowledge of definitions, notations.

2. Techniques and skills.

3. Translation of data.

4. Comprehension.

5. Inventiveness.

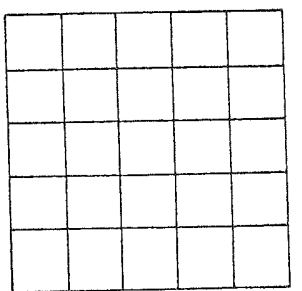

FICURE 2: Levels of Cognitive Complexity in Mathematics

The intersection of the cognitive level and content topic The in of jective of instruction (e.g. knowledge of a techhique nique for proving a particular theorem). ordinary level courses and college service courses in mathematics. Another suggestion for teachers/lecturers on such courses is that they set objective questions and performance standards that are within reach of most of the students. This in post-primary schools sugestion is unlikely to be feasible in post-prinary schools mathematics where the public examination systen is designed to achieve a nice 'normal distribution' of mathematics scores with means and standard deviations so as to facilitate grading the recent formation of a Curriculum and Examinations Board may herald a move towards a more beneficial approach to goalsetting and assessment.

Type and Amount of Instruction: Here we come to consider briefly the categories of variables which are at the hub of the mathematical education process. With the development of many alternative instructional models (e.g. discovery learning, inductive thinking. inquiry training, advance organisers, to name a few) and a burgeoning educational technology (visual projection devices, micro-computerss, T.V. and videotape, programmed texts, copying devices etc.) one might have expected that, the traditional teaching approaches of a series of lecture/ chalk and talk sessions and assignments to large groups of stud ents, would be on the wane. Not so, according to many obser vers. Although I cannot quote any Irish research survey it is unlikely that mathematics instruction here is any less traditional than in the U.S. where a 1977 National Science Foundation study of approximately 5,000 secondary school classrooms revealed that the predominant instructional pattern is teacher explanation followed by pupil work on class assignments [6]. It is probably fair to say that in our third-level colleges and universities, apart from some advanced mathematics courses, the predominant instructional style is still that of lecture series and occasional seminars. Such an inflexible and unresponsive learning environment promotes mediocre learning and poor study habits at all levels of mathematics education. A number of educationists [9] argue that with the advent of computer-based education the opportunity will shortly exist to provide students in many student areas, including mathematics, with a learning environment in which (1) they have much more more control over what they learn, and the rate at which learning material is presented and, over the time of instruction and assessment, (2) they obtain better and more regular feedback on performance. The instructor will be freed to do higher level work such as course development and management, Individual consultation, group discussion, etc.

Characteristics of the Learners: It makes good sense in providing mathematics courses to take account of individual differences. Many pupils come to mathematics courses already know ing quite a lot of the content to be learned, others come to mathematics courses without various prerequisite mathematical concepts and skills. Such differences can be easily accomodated in instructional provision but are often ignored. Other 
individual differences which are related to mathematics performance, such as spatial and logical reasoning [8], cognitive style [5], and internal structure of mathematical knowledge [2] are less easily accommodated but may, with further investigation, become more accessible variables.

In conclusion. I would suggest that although the provision of mathematics education is a complex process, there is scope for substantial improvement through changes in instructional variables such as those described above, a willingness to try new approaches, and a cooperative spirit among mathematics teachers at primary, secondary and third levels of education.

\section{References}

1. Begle, E.G. Critical Variables in Mathematics Education: Findings from a Survey of the Literature. Mathematical Association of America. National Council of Teachers of Mathematics (1979).

2. Branca, N.A. Communication of Mathematical Structure and its Relationship to Achievement. Journal for Research in Mathematics Education, 6, 37-69 (1980).

3. Brennan, M. School Mathematics - Knocking on Heaven's Door. Irish Mathematical Society Newsletter, 6, (1982).

4. Bruce, J.W. Group Theory and Other Abstract Tripe. Irish Mathematical Society Newsletter, 5. (1982).

5. Fennema, E. and Behr, M.J. Individual Differences and the Learning of Mathematics. In R.J. Shumway (Ed.) Research in Mathematics Education, Reston, V.A. : National Council of Teachers of Mathematics (1980).

6. Fey, J.T. Mathematics Teaching Today: Perspectives from Three National Surveys. Mathematics Teacher, 72, 7 (1979).

7. Husen, T. International Study of Achievement in Mathematics. New Yorl: Wiley (1967).

8. Krutetskil, V.A. The Psychology of Mathematical Abilities in School Children. (J. Kilpatrick and I. Wirsup, Eds.) Chicago University Press (1976).

9. Mitzel, H. On the Importance of Theory in Applying Technology to Education. Journal of Computer-Based Instruction. 7. 4 (1981).

10. O'Murchu, N. and O'Sullivan, C.T. Mathematical Horses for Elementary Physics Courses. Irisin Mathematical Society Newsletter, 6 (1982).

11. Shulman, L.S. Psychology and Mathematics Education. In: E.G. Begle, Ed.). Mathematics Education. Yearbook of National Society for the Study of Education (1970).

Education Depantment,

St. Patrick's College,

Drumcondra,

Dublin 9.

\section{COMFUTERS IN THE TEACHING OF MATHEMATICS AT UCD}

Colin D. Walten

In common with many other university mathematics departments, a considerable portion of our effort is involved with service teaching of first year courses. Much of this consists of rote techniques such as solving linear equations, inverting matrices, differentiating polynomial functions, and curve sketching of rational functions. These are all, with more or less ease, amenable to programming as tutorial sessions on a computer. The advantages are clear: a uniform procedure is taught to everyone, and each student can practice as much as necessary whenever he wishes. In this way the tutorial system can be extended, less dependence need be placed on tutors, and some formal tutorials can be replaced by sessions where 